\title{
ORIGINAL
}

\section{VIGILANCIA INDIVIDUALIZADA DE LOS CASOS INICIALES DE INFECCIÓN POR GRIPE PANDÉMICA (H1N1) 2009 EN ESPAÑA, ABRIL-JUNIO 2009}

\author{
Patricia Santa-Olalla Peralta (1), Marta Cortes García (1), Elena Vanessa Martínez Sánchez (2), \\ Francisco Nogareda Moreno (2), Aurora Limia Sánchez (1), Isabel Pachón del Amo (1) y Ma José \\ Sierra Moros (1), en nombre del Subcomité de Vigilancia Epidemiológica del Plan Nacional de \\ Preparación y Respuesta ante una Pandemia de Gripe. \\ (1) Centro de Coordinación de Alertas y Emergencias Sanitarias (CCAES), Dirección General de Salud Pública y \\ Sanidad Exterior, Ministerio de Sanidad y Política Social. \\ (2) Centro Nacional de Epidemiología, Instituto de Salud Carlos III, Ministerio de Ciencia e Innovación.
}

\section{RESUMEN}

Fundamento: En abril de 2009 se inició en España una nueva estrategia de vigilancia con el objetivo de detectar los casos originados por el virus pandémico (H1N1) 2009 y de implementar las medidas de control adecuadas para contener su transmisión. Se describen las características clínicas y epidemiológicas de los casos confirmados en España notificados por la Red Nacional de Vigilancia Epidemiológica desde el 24 Abril al 30 Junio 2009.

Métodos: Como parte de la respuesta inicial de vigilancia a la pandemia, a nivel nacional se recogió información clínica y epidemiológica individualizada de todos los casos en investigación de infección por virus pandémico (H1N1) 2009, así como de sus contactos.

Resultados: De los 717 casos confirmados el $91 \%$ fueron notificados por 5 Comunidades Autónomas. A 15 de junio de 2009 el $49,1 \%$ de los casos pertenecían a brotes en centros educativos. No se detectaron brotes nosocomiales. La mediana de período de incubación fue de 3 días. El 88\% de los casos tenía menos de 30 años y el $24,9 \%$ eran importados. Los síntomas más frecuentes fueron tos $(92 \%)$ y fiebre $(81,8 \%)$. La mediana de duración de síntomas fue de 5 días. Trece casos requirieron ingreso hospitalario y uno falleció.

Conclusiones: Durante los primeros meses de pandemia los casos de gripe pandémica presentaron un cuadro leve similar al de la gripe estacional que afectó mayoritariamente a niños y adultos jóvenes. A finales de junio 2009 la aparición de brotes en diferentes colectivos reflejaba la penetración del virus pandémico en la comunidad y el inicio de su circulación.

Palabras clave: Brote. Pandemia. Subtipo H1N1 del Virus de la Influenza A. Gripe humana. España. Vigilancia poblacional.

\section{Correspondencia:}

Patricia Santa-Olalla Peralta

Centro de Coordinación de Alertas y Emergencias Sanitarias (CCAES)

Dirección General de Salud Pública y Sanidad Exterior

Ministerio de Sanidad y Política Social

Paseo del Prado, 18-20

28071 Madrid.

psantaolalla@msps.es

\section{ABSTRACT}

\section{Enhanced surveillance of initial cases of pandemic influenza (H1N1) 2009 infection in Spain, April-June 2009}

Background: In April 2009, a new surveillance strategy for the detection of cases of pandemic influenza (H1N1) 2009 infection and for the implementation of appropriate control measures to contain its transmission was initiated in Spain. We describe the clinical and epidemiological characteristics of confirmed cases in Spain notified by the National Epidemiological Surveillance Network from April 24 to June 30, 2009.

Methods: As part of the initial surveillance response to the pandemic, case-based clinical and epidemiological information was collected nationwide on cases under investigation for pandemic virus (H1N1) 2009 infection and their contacts.

Results: Of 717 confirmed cases, $91 \%$ were notified by 5 Autonomous Communities. As of June 15, $49.1 \%$ of cases belonged to school outbreaks. No nosocomial outbreaks were detected. The median incubation period was 3 days. Eighty-eight percent of cases were under the age of 30 years, and $24.9 \%$ were imported. The most frequent symptoms were cough $(92 \%)$ and fever $(81.8 \%)$. The median duration of symptoms was 5 days. Thirteen cases required hospitalization and one died.

Conclusions: During the first months of the pandemic, pandemic influenza cases experienced a mild illness similar to seasonal influenza, predominantly affecting children and young adults. By the end of June 2009, the detection of outbreaks in different settings indicated the diffusion of the pandemic virus into the community and the start of its circulation.

Key words: Epidemiology. Disease Outbreaks. Influenza A virus, H1N1 subtype. Grippe. Influenza, human. Spain. Pandemic. Population Surveillance. 


\section{INTRODUCCIÓN}

El 25 de abril de 2009 la Organización Mundial de la Salud (OMS) calificó el brote por el nuevo virus de gripe $\mathrm{A}(\mathrm{H} 1 \mathrm{~N} 1)$ de origen porcino notificado en los Estados Unidos$^{1}$ y México 2 como Emergencia de Salud Pública de Importancia Internacional (ESPII) bajo el Reglamento Sanitario Internacional $(2005)^{3,4}$. El nivel de alerta pandémica pasó a fase 4 el 27 de abril y a fase 5 el 29 de abril de 2009. El 11 de junio de 2009 la OMS elevó el nivel de alerta a fase 6 tras considerar la existencia de transmisión elevada y mantenida del virus en el mundo ${ }^{5}$.

En España, el Centro de Coordinación de Alertas y Emergencias Sanitarias (CCAES) del Ministerio de Sanidad y Política Social (MSPS), tras recibir la alerta sobre este brote el 24 de abril de 2009 , recomendó reforzar los sistemas de vigilancia epidemiológica. A partir de este momento se adaptó la definición de caso del Plan Nacional de Preparación y Respuesta ante una pandemia de gripe y los protocolos de actuación y manejo de casos y contactos, y de control de la infección para distribuir al Sistema Sanitario e Instituciones implicadas ${ }^{6}$. El seguimiento y vigilancia del desarrollo del brote en España se llevó a cabo en el CCAES, junto con el Centro Nacional de Epidemiología, Instituto de Salud Carlos III (ISCIII) y de forma coordinada con las Comunidades Autónomas (CCAA) a través del Subcomité de Vigilancia Epidemiológica del Plan Nacional de Preparación y Respuesta ante una Pandemia de Gripe.

El 26 de abril de 2009 se notificaron al CCAES los tres primeros casos en investigación de infección por virus pandémico (H1N1) 2009, todos con antecedentes de viaje a México y que cumplían la definición de caso. El 27 de abril de 2009 España notificó el primer caso confirmado por laboratorio en Europa de infección por el virus pandémico (H1N1) 2009 en un viajero procedente de Méjico $^{7}$.
El objetivo de este artículo es describir y analizar las características clínicas y epidemiológicas de los casos de infección por el virus pandémico (H1N1) 2009 notificados al CCAES por la Red Nacional de Vigilancia Epidemiológica desde el 24 Abril de 2009 al 30 de Junio 2009.

\section{MATERIAL Y MÉTODOS}

Sujetos. Con el objetivo de detectar los casos de gripe originados por el nuevo virus y de implementar las medidas de control adecuadas y contener su transmisión, se diseñó e implementó una nueva estrategia de vigilancia apoyada sobre la Red Nacional de Vigilancia Epidemiológica.

- Se consideró caso sospechoso o en investigación a cualquier persona que cumpliera los criterios clínicos y epidemiológicos desde el 24 de abril de 2009 (tabla 1). La definición de caso inicial fue modificada, $y$, finalmente aprobada el 7 mayo de 2009, para adaptarse a la propuesta por el European Centre for Disease Prevention and Control (ECDC) y la Unión Europea ${ }^{8}$. Las modificaciones incluyeron cambios en: el punto de corte para la fiebre (se pasó de $37,5^{\circ} \mathrm{C}$ a $38^{\circ} \mathrm{C}$ ), duración del período de incubación (de 10 días se reduce a 7) y la inclusión, como área de riesgo adicional, de los EEUU.

- Se consideró contacto estrecho a las personas que durante el periodo de transmisión del caso (entre un día antes del inicio de síntomas y mientras se mantuviera la clínica, con un mínimo de 7 días): 1.Convivieran con él; 2. Hubieran mantenido contacto directo a distancia inferior de 1 metro; 3. Hubieran compartido viaje de avión en la misma fila o en las dos anteriores o posteriores a la del caso. También se consideró contacto estrecho, al personal sanitario que hubiera 
Tabla 1

Definición de caso y clasificación para la infección por el virus de la gripe (H1N1) 2009, España, 24 Abril- 30 Junio 2009

\begin{tabular}{|c|c|}
\hline $\begin{array}{l}\text { Periodo de } \\
\text { incubación }\end{array}$ & 10 días* \\
\hline Criterios Clínicos & $\begin{array}{l}\text { Cualquier persona que cumpla alguna de las siguientes condiciones: } \\
\left.\text { - Fiebre }>0=37,5^{\circ} \mathrm{C}\right)^{*} \mathrm{Y} \text { signos o síntomas de infección respiratoria } \\
\text { aguda } \\
\text { - Neumonía (infección respiratoria grave) } \\
\text { - Fallecimiento por una enfermedad respiratoria aguda de causa desconocida }\end{array}$ \\
\hline $\begin{array}{l}\text { Criterios } \\
\text { Epidemiológicos }\end{array}$ & $\begin{array}{l}\text { Cualquier persona que cumpla alguna de las siguientes condiciones en los } \\
10 \text { días* previos a la aparición de síntomas: } \\
\text { - Haber estado o visitado un área donde se han declarado casos humanos } \\
\text { por nuevo virus de la gripe A/H1N1 (México*). } \\
\text { - Haber estado en contacto cercano con una persona diagnosticada como } \\
\text { caso confirmado de nuevo virus de la gripe A/H1N1. } \\
\text { - Haber estado en contacto cercano con animales sospechosos o confirma- } \\
\text { dos de infección por gripe porcina (Este criterio fue sustituido el } 27 \\
\text { Abril } 2009 \text { por: «Trabajar en laboratorio y manipular muestras poten- } \\
\text { cialmente contaminadas»). }\end{array}$ \\
\hline $\begin{array}{l}\text { Criterios de } \\
\text { Labortorio }\end{array}$ & $\begin{array}{l}\text { Al menos una de las siguientes pruebas positivas: } \\
\text { - Detección por RT- PCR de nuevo virus de la gripe A/H1N1. } \\
\text { - Aumento de } 4 \text { veces el título de anticuerpos neutralizantes frente a nue- } \\
\text { vo virus de la gripe A/H1N1 (implica la necesidad de dos tipos de suero, } \\
\text { uno de la fase aguda de la enfermedad y otro de la fase convaleciente -10 } \\
\text { a } 14 \text { días posteriores). } \\
\text { - Cultivo viral de nuevo virus de la gripe A/H1N1. }\end{array}$ \\
\hline $\begin{array}{l}\text { Clasificación } \\
\text { de caso }\end{array}$ & $\begin{array}{l}\text { A. CASO EN INVESTIGACIÓN } \\
\text { Cualquier persona que cumpla criterios clínicos Y epidemiológicos } \\
\text { B. CASO PROBABLE } \\
\text { Cualquier persona que cumpla los criterios clínicos Y epidemiológicos Y } \\
\text { presente infección por virus de la gripe A no subtipable como virus H1 hu- } \\
\text { mano. } \\
\text { C. CASO CONFIRMADO } \\
\text { Cualquier persona con confirmación de laboratorio de nuevo virus de la } \\
\text { gripe A. }\end{array}$ \\
\hline
\end{tabular}

* La definición de caso aprobada el 7 mayo de 2009 incluye las siguientes modificaciones: el punto de corte para la fiebre pasa $\mathrm{a} \geq 38^{\circ} \mathrm{C}$, la duración del período de incubación se reduce a 7 días y se incluye los EEUU como área de riesgo. Las áreas de riesgo se ampliarían en función de la evolución de la pandemia. 
atendido casos sin mantener las medidas de protección personal adecuadas.

\section{Actuaciones para el manejo de casos y contactos}

- Ante cualquier caso sospechoso o en investigación se debían seguir las recomendaciones de control de la infección y proceder al aislamiento respiratorio y de contacto del caso (bien en hospital o en el domicilio). Se administraría tratamiento con inhibidores de la neuraminidasa (oseltamivir o zanamivir) en las 48 horas posteriores al inicio de síntomas, según pauta indicada en la ficha técnica. En todos los casos en investigación debían tomarse muestras clínicas para su confirmación por el Centro Nacional de Microbiología (ISCIII) y notificarse de forma urgente al CCAES por correo electrónico o fax, enviando ficha de notificación (anexo I).

- Se debían identificar los contactos estrechos de cualquier caso en investigación, vigilando de forma activa la presentación de sintomatología compatible y notificándose de forma urgente en su caso. Se debía administrar profilaxis con inhibidores de la neuraminidasa y se recomendó cuarentena domiciliaria durante 10 días con restricción de visitas y uso de mascarilla quirúrgica.

El 20 de mayo 2009 el Subcomité de Vigilancia Epidemiológica del Plan Nacional de Preparación y Respuesta ante una Pandemia de Gripe acordó que únicamente se daría tratamiento con antivirales a los casos que requirieran hospitalización o a los que tuvieran un riesgo más elevado de sufrir complicaciones por gripe (tabla 2). Se suspendió la cuarentena de los contactos y se recomendó profilaxis sólo a aquellos perso- nas con riesgo de sufrir complicaciones por gripe.

Posteriormente, el 12 de junio 2009, se acordó que no sería necesario identificar, realizar seguimiento ni administrar profilaxis a los contactos de los casos detectados. Además, en los brotes sólo se confirmarían los primeros casos y no sería necesaria la notificación de forma individualizada de todos los casos del brote. Se notificaría el inicio y la evolución del mismo, y se enviaría un informe final del brote.

\section{Confirmación de los casos}

La confirmación de los casos se realizó mediante técnicas moleculares específicas para el virus pandémico (H1N1) 2009 (RTPCR seguida de la secuenciación del gen NP). Los casos comenzaron confirmándose en el Centro Nacional de Microbiología (CNM), Centro Nacional de Referencia para Gripe de la OMS. A partir del 1 de mayo de 2009 los Laboratorios de Referencia de las CCAA comenzaron a realizar las pruebas iniciales para diagnóstico y el CNM confirmó dichos resultados. El 10 de junio de 2009 el Subcomité de Vigilancia Epidemiológica del Plan Nacional de Preparación y Respuesta ante una Pandemia de Gripe acordó que los laboratorios de microbiología de los hospitales de las CCAA podrían confirmar casos de enfermedad por virus pandémico (H1N1) 2009, y únicamente se enviaría de forma aleatoria al CNM muestras para estudios genéticos.

\section{Recogida de datos y análisis}

La información sobre los casos y sus contactos fue recogida por los Servicios de Epidemiología y/o Alertas de las CCAA mediante un formulario de notificación que incluía variables demográficas, características clínicas y de evolución, características epidemiológicas, factores de riesgo 
Grupos de población de alto riesgo de complicaciones por gripe. Subcomité de Vigilancia, 10 junio 2009*

Se consideran personas con alto riesgo de sufrir complicaciones en caso de tener infección por este nuevo virus de la gripe $\mathrm{A}(\mathrm{H} 1 \mathrm{~N} 1)$ a los siguientes:

- Adultos de 65 años o más

- Personas de cualquier edad con una condición clínica especial que le predisponga a tener una gripe complicada:

- Enfermedad crónica (enfermedades crónicas cardiovasculares -excepto la hipertesión-) o pulmonares (incluyendo displasia bronco-pulmonar, fibrosis quística y asma); enfermedades metabólicas (incluyendo diabetes mellitus); insuficiencia renal; hemoglobinopatías y anemias; asplenia; enfermedad hepática crónica; enfermedades neuromusculares graves o inmunosupresión, incluida la originada por la infección de VIH o por fármacos o en los receptores de trasplantes.

- Niños/as y adolescentes, menores de 18 años, que reciben tratamiento prolongado con ácido acetil salicílico, por la posibilidad de desarrollar un síndrome de Reye tras la gripe.

- Mujeres embarazadas.

* A finales de junio 2009, se excluyó de los grupos de población de alto riesgo a las personas de 65 años o más; y a finales de julio 2009 se incluyó como factor de riesgo la obesidad mórbida.

(incluyendo embarazo y ocupacionales), de diagnóstico microbiológico, tratamiento y profilaxis (Anexos 1 y 2). La información agregada de los brotes se recogió en un formulario de notificación específico (Anexo 3). La información así recogida fue enviada al CCAES para su revisión y análisis.

El análisis descriptivo de los datos se realizó con Excel y el paquete estadístico SPSS v.17.0. Las proporciones se calcularon como porcentajes de los casos con información disponible.

\section{Aspectos éticos}

Tanto los protocolos de vigilancia como el formulario de notificación de casos fueron aprobados por la Comisión de Salud Pública del Ministerio de Sanidad y Política Social. Esta investigación formó parte de la respuesta de salud pública a la pandemia de gripe 2009 por lo que no fue necesaria una evaluación ética específica.

\section{RESULTADOS}

Del 24 Abril al 30 junio de 2009 se notificaron al CCAES un total de 717 casos confirmados en toda España de infección por virus pandémico (H1N1) 2009. De éstos, 543 casos $(75,7 \%)$ fueron confirmados por el CNM y el resto por los Laboratorios de Referencia de las CCAA. El 91\% de los casos fueron notificados por 5 Comunidades Autónomas. El 68\% del total de casos pertenecían a una sola Comunidad Autónoma.

Se analizó la información de 582 casos para los que se disponía de cuestionario de notificación. El primer caso fue notificado el 26 de abril y confirmado el 27 de abril de 2009. De los casos notificados en este período $13(1,8 \%)$ requirieron ingreso hospita- 


\section{Figura 1}

Casos confirmados por fecha de inicio de síntomas, origen y pertenencia a un brote, 18 abril- 20 de junio de $2009(n=689)$
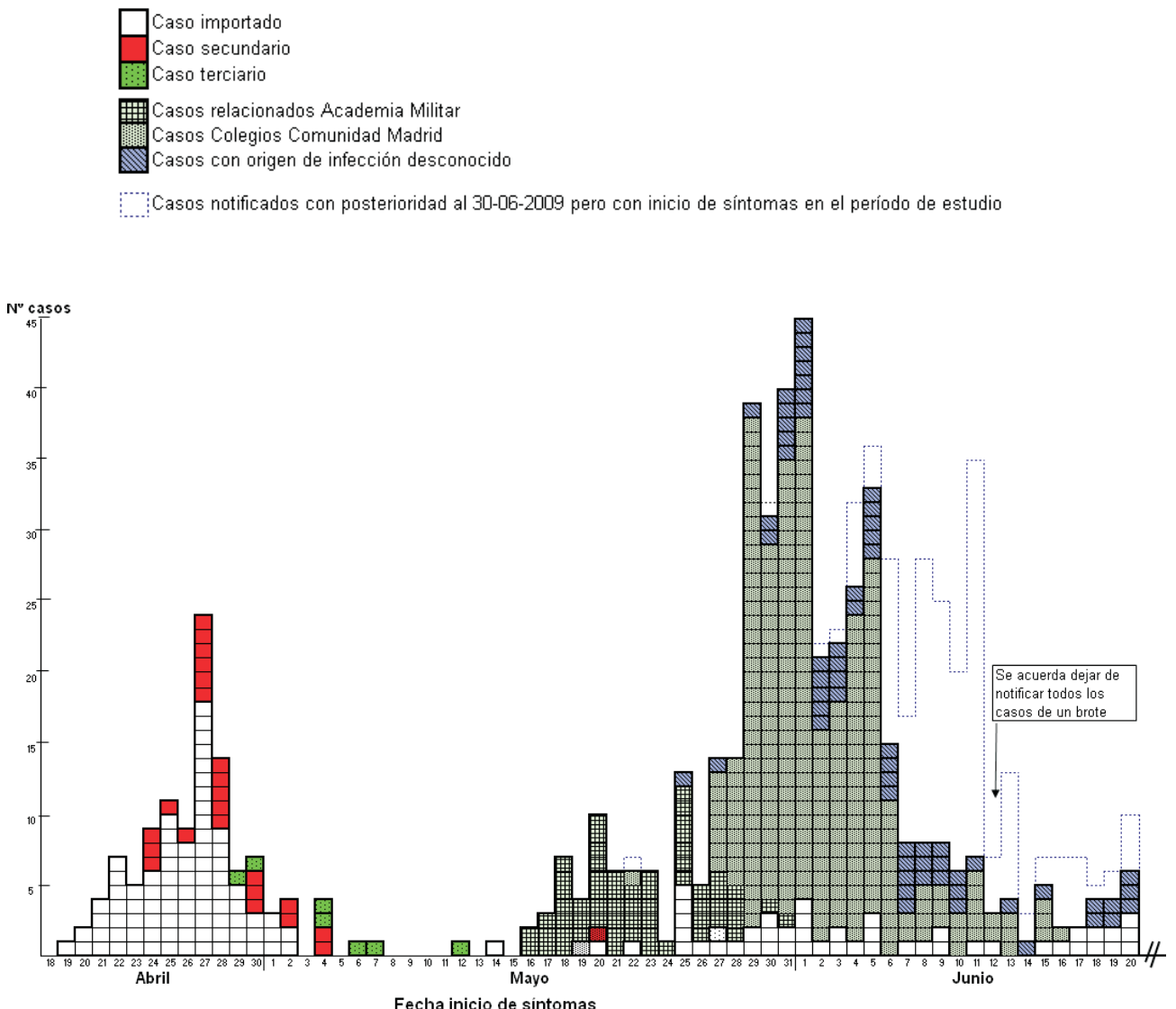

lario por la gravedad del cuadro presentado, 6 de ellos en UCI. El 30 de junio de 2009 falleció la primera persona en España por infección por el virus pandémico (H1N1) 2009.

\section{Características epidemiológicas}

La fecha de inicio de síntomas de los casos declarados en el período de estudio está comprendida entre el 19 de abril y el 28 de junio de 2009. En la figura 1 se observa la distribución de casos confirmados hasta el 20 de junio de 2009 según fecha de inicio de síntomas, origen (importado o autóctono) y pertenencia a un brote.

Hasta el 15 de mayo de 2009 el 73,7\% (84) de los casos notificados eran importados. Al final del período de estudio este porcentaje disminuyó al 24,9\% (144 de los 578 casos de los que se dispone de esta información) (figura 1). La fecha de regreso de los casos con antecedentes de viaje estuvo comprendida entre el 20 de abril y el 28 de junio 
de 2009. Los países de procedencia fueron principalmente México (en 79 casos) y Estados Unidos (en 40). Durante el mes de junio 2009 comenzaron a notificarse casos procedentes de otros países: países del área del Caribe (13 casos) y europeos como Reino Unido (6 casos). De los casos para los que se dispone de información sobre la presencia de síntomas $(\mathrm{n}=100)$, un 39\% los presentaron durante el viaje de regreso.

Como puede observarse en la curva epidemiológica (figura 1), a partir del 15 de mayo 2009 comenzaron a identificarse varios brotes comunitarios. El primero de ellos se produjo entre el 16 y el 31 de mayo en una Academia Militar en la Comunidad de Madrid, con limitada diseminación entre los contactos familiares de los reclutas. Posteriormente, se notificaron varias agrupaciones de casos en diferentes colegios de la Comunidad de Madrid, la mayoría de ellos relacionados con un primer brote que se inició en un centro escolar cuyo caso primario tenía antecedentes de viaje a Estados Uni- dos. En este primer centro escolar se notificaron un total de 126 casos. En la figura 1 se han incorporado de forma retrospectiva (en línea punteada) los casos que iniciaron síntomas durante el período de estudio, pero que fueron notificados con posterioridad. La curva está truncada a 20 de junio 2009 y el descenso de casos que se observa a partir del 13 de junio no es real, dada la imposibilidad de recoger de forma oportuna la información relativa a estos casos. Al final de junio de 2009 comenzaron a notificarse brotes en otros colectivos, principalmente en campamentos de verano y en viajeros de grupos organizados a diferentes destinos nacionales y del extranjero.

Entre los casos autóctonos, el lugar de adquisición de la infección fue diferente según el período de tiempo analizado. Como puede observarse en la figura 2 , mientras que en las primeras semanas, hasta el 15 mayo de 2009 , toda la transmisión autóctona se producía en el entorno familiar, en las semanas siguientes se observó un predominio de la

Figura 2

Lugar o fuente de adquisición de la infección por el virus de la gripe A (H1N1) 2009,

España, 24 Abril- 15 Junio 2009 ( $N=529)$

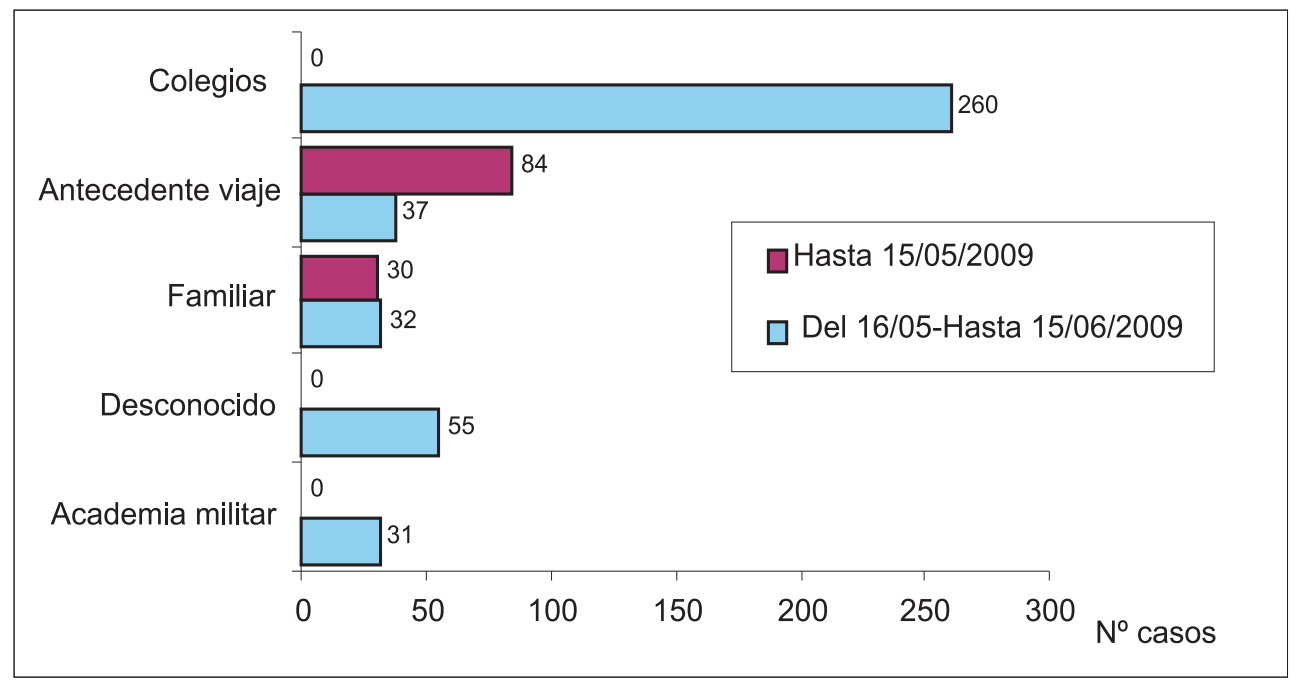


Figura 3

Distribución de casos por edad y sexo $(\mathrm{N}=579)$

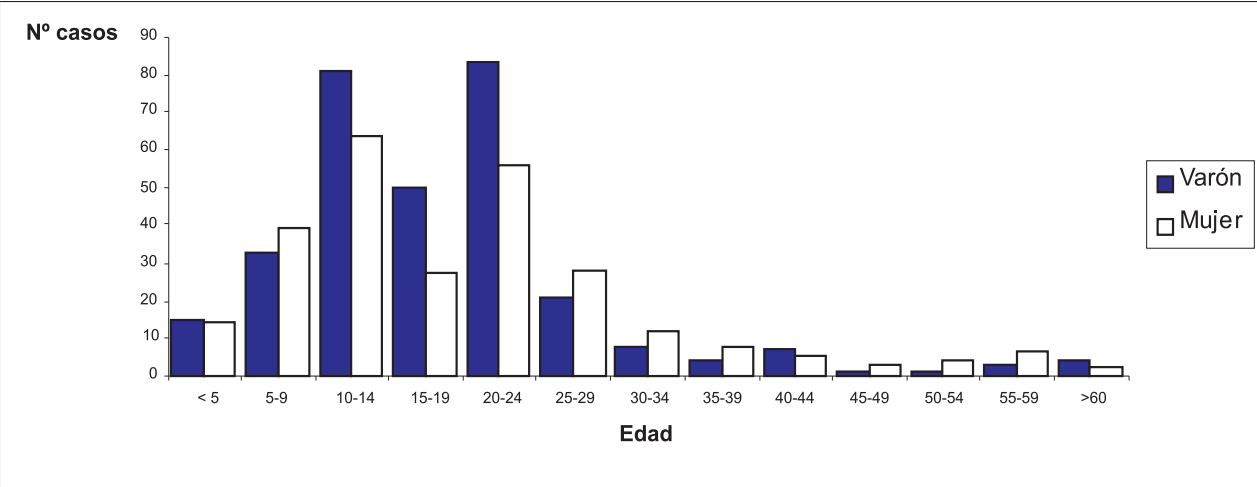

transmisión autóctona en centros educativos o instituciones semicerradas (en 291 casos) al mismo tiempo que la transmisión en el entorno familiar perdió importancia (32 casos desde el 15 de mayo 2009). Durante el mes de junio 2009 se comenzó a notificar un número creciente de casos para los que no se podía establecer el origen o fuente de la infección (55 casos a 15 de junio 2009) (figuras 1 y 2).

En el período de estudio no se notificó ningún brote nosocomial. A 30 junio de 2009 se habían notificado 10 casos aislados entre trabajadores sanitarios, de los cuales 5 tenían antecedentes de viaje a áreas de riesgo. A estos casos se añadieron 14 pertenecientes a un brote entre trabajadores de un hospital que acudieron a una fiesta, sin que se diera posteriormente transmisión nosocomial.

Sin contabilizar los casos de los brotes, hasta el 15 de mayo de 2009 se identificaron y siguieron más de 2.000 contactos en España, de los cuales 35 se confirmaron como casos secundarios sin antecedentes de viaje y 9 como casos terciarios. En su mayoría, se trataba de familiares y amigos de los casos primarios. El estudio y seguimiento de estos contactos permitió estimar una mediana de tiempo de generación de 3 días (rango de 1 a 7 días) y una mediana de periodo de incubación de 3 días (rango de 1 a 7 días).

\section{Características demográficas y clínicas}

La edad media de los casos $(n=579)$ fue de 19,02 años, con una mediana de 16 años y un rango de 0 a 74 años. De ellos 313 $(53,8 \%)$ eran varones. La distribución de casos por edad y sexo puede observarse en la figura 3.

Los síntomas notificados con más frecuencia fueron tos $(92 \%)$ y fiebre $(81,8 \%)$. En la tabla 3 se presenta la distribución de los síntomas detectados en los casos confirmados. Con la información disponible se estimó una mediana de duración de síntomas de 5 días (rango de 1 a 13).

La información sobre el estado de vacunación previo con la vacuna de la gripe estacional 2008-09 estuvo disponible para 347 casos $(59,6 \%), 44$ habían sido vacunados mientras que el resto no tenían antecedentes de vacunación. 
Tabla 3

Características clínicas de los casos confirmados de gripe pandémica (H1N1) 2009, España, 24 Abril- 30 Junio 2009

\begin{tabular}{|l|c|c|}
\hline \multicolumn{1}{|c|}{ Síntomas } & Número de casos & $\begin{array}{c}\text { \% casos con síntomas } \\
\text { sobre el total de casos } \\
\text { con información }\end{array}$ \\
\hline Tos & 505 & $92 \%(505 / 549)$ \\
\hline Tos seca & 65 & $62,5 \%(65 / 104)$ \\
\hline Tos productiva & 21 & $20,4 \%(21 / 103)$ \\
\hline Fiebre & 463 & $81,8 \%(463 / 566)$ \\
\hline Malestar general & 330 & $74,7 \%(330 / 442)$ \\
\hline Cefalea & 320 & $63,4 \%(320 / 505)$ \\
\hline Rinorrea & 289 & $60,6 \%(289 / 477)$ \\
\hline Dolor de garganta & 288 & $58,2 \%(288 / 495)$ \\
\hline Mialgia & 269 & $56,4 \%(269 / 477)$ \\
\hline Estornudos & 30 & $29,7 \%(30 / 101)$ \\
\hline Dolor articular & 26 & $26,5 \%(26 / 98)$ \\
\hline Diarrea & 77 & $17,2 \%)(77 / 447$ \\
\hline Dificultad respiratoria & 72 & $15,9 \%(72 / 452)$ \\
\hline Conjuntivitis & 14 & $14,1 \%(14 / 99)$ \\
\hline Vómitos & 45 & $10,3 \%(45 / 436)$ \\
\hline Náuseas & 8 & $8,4 \%(8 / 95)$ \\
\hline Neumonía & 19 & $4,9 \%(19 / 385)$ \\
\hline Sangrado nasal & 2 & $2 \%(2 / 99)$ \\
\hline
\end{tabular}

\section{Evolución y complicaciones}

La mayoría de los casos presentaron un cuadro clínico leve/moderado con buena evolución hacia la recuperación, similar al de la gripe estacional. Sin embargo, 13 personas requirieron ingreso hospitalario por la gravedad del cuadro presentado. La edad media de los casos hospitalizados fue de 30,2 años, con una mediana de 32 y un rango de 8 a 66 años. Diez de ellos presentaron una neumonía viral primaria, de los que 5 requirieron ingreso en UCI y 4 de ellos ventilación mecánica. Dos casos presentaron coinfección bacteriana secundaria. Además, otro caso ingresó en UCI por fracaso renal, coagulación intravascular diseminada y síndrome de distress respiratorio agudo (SDRA), que requirió ventilación mecánica. Este caso tenía antecedentes personales de cáncer. Otros dos pacientes que ingresaron en UCI tenían antecedentes personales de asma y embarazo en el tercer trimestre de gestación en un caso y en otro obesidad mórbida. De los 7 casos hospitalizados que no ingresaron en UCI, 3 presenta- 
ban patología o factores de riesgo: una mujer embarazada con asma y 2 personas con patología pulmonar.

El 30 de junio de 2009 falleció la primera persona por infección por el virus pandémico (H1N1) 2009 en España. Se trataba de una mujer de 20 años, embarazada de 29 semanas y con antecedentes de asma. Ingresó directamente en UCI a los 6 días del inicio de síntomas por infección respiratoria de mala evolución e hipoxemia grave que requirió ventilación mecánica. La mujer falleció a los 15 días de su ingreso. No tenía antecedentes de viaje reciente ni de contacto con otro caso de gripe por el virus pandémico (H1N1) 2009.

\section{Tratamiento antiviral}

La información sobre el tratamiento y profilaxis con fármacos antivirales recibidos fue cumplimentada de forma deficiente por lo que los resultados no son valorables. En el período de estudio no se describió ninguna reacción adversa a los antivirales (oseltamivir o zanamivir). Asimismo, no se identificó ninguna cepa con resistencia a los inhibidores de la neuraminidasa.

\section{DISCUSIÓN}

España fue el primer país en Europa que notificó un caso confirmado de gripe pandémica (H1N1) 20097. Varios factores pueden haber contribuido a esta identificación temprana de casos. Por un lado, la rápida emisión de una alerta epidemiológica a la Red Nacional de Vigilancia Epidemiológica (alerta que tuvo una gran cobertura mediática), permitió sensibilizar a los profesionales de salud pública y del sistema asistencial, así como a la población. Por otro lado, España cuenta con un sistema de vigilancia epidemiológica muy eficiente y la distribución con la alerta de una definición de caso sensible hizo posible la rápida detección de los casos al inicio del brote, así como el seguimiento de más de 2.000 contactos.

La epidemiología de los casos iniciales de gripe pandémica (H1N1) 2009 en España fue similar a la descrita en otros países de nuestro entorno ${ }^{9-13}$. La mayoría de los casos fueron niños y adultos jóvenes por debajo de 30 años $(88 \%)$, lo que inicialmente reflejaba la estructura de edad de los viajeros que regresaban de México y EEUU y, posteriormente, de los brotes en centros educativos.

Es de destacar el alto porcentaje de casos importados, un 39\%, que presentaron síntomas durante el viaje de regreso. Sin embargo, ninguno de estos casos fue identificado en frontera. Este dato debería tenerse en cuenta a la hora de decidir la implementación de las medidas de contención en puertos y aeropuertos en aquellas infecciones con elevada capacidad de transmisión, que cursan con un cuadro clínico leve o paucisintomático y para las que la identificación de los casos sintomáticos se base en la autodeclaración de síntomas por parte del pasajero o transeúnte.

A principios de junio 2009 casi la mitad $(49,1 \%)$ de los casos notificados en toda España pertenecían a brotes detectados en centros educativos. No todos los casos pertenecientes a estos brotes están recogidos en la curva epidémica, dado que no era necesaria su notificación. A partir del 6 de junio se observó un retraso en la notificación de los casos debido a su gran número, lo que se refleja en la curva en forma de línea punteada (figura 1). A diferencia de Reino Unido, donde la afectación de centros educativos se produjo en las semanas iniciales de la alerta $^{9,13}$ condicionando la posterior transmisión comunitaria en ese país, en España la introducción del virus en los colegios fue más tardía y coincidió con el final del curso escolar, lo que favoreció su control, y una disminución de la velocidad e intensidad de la transmisión comunitaria. 
A final del mes de junio de 2009 se observó una situación epidemiológica dispar en España. Mientras que 5 CCAA notificaban el $91 \%$ de los casos, en la mayoría circunscritos a brotes de diferente tamaño, en otras, por el contrario, se detectaban pocos casos (por ejemplo en 5 CCAA sólo 1 caso o ninguno en 3 CCAA). Esta situación epidemiológica con desigual penetración del virus en la comunidad condicionó la estrategia de vigilancia en España y el 26 de junio de 2009 se aprobó una nueva estrategia de transición hacia la «vigilancia en pandemia» (fase de mitigación), que contempló la diferente situación epidemiológica de las CCAA en España. Esta estrategia permitía abandonar la vigilancia individualizada de casos en la comunidad en aquellas CCAA con una mayor transmisión comunitaria y centraba la vigilancia de la infección por el virus pandémico (H1N1) 2009 en la información proporcionada por el sistema de vigilancia de gripe estacional (sistema centinela), en la vigilancia de agrupaciones de casos de infección respiratoria aguda, en el seguimiento de gripe o enfermedad respiratoria aguda a partir de las bases informatizadas de Atención Primaria y servicios de urgencia y en la vigilancia individualizada de casos hospitalizados.

La mayoría de los casos confirmados en los primeros meses de pandemia en España presentaron un cuadro clínico leve/moderado, similar al de la gripe estacional, con tos y fiebre como síntomas predominantes. Sin embargo, con el aumento del número de casos y la ampliación de los grupos de edad afectados, se registró un aumento de casos que requirieron ingreso hospitalario, principalmente por neumonía vírica. Es importante resaltar que la mediana de edad de los casos que requirieron hospitalización fue superior a la de los casos que no la requirieron (32 años frente a 16 años).

La información sobre el tratamiento y profilaxis antiviral recibidos es deficiente por lo que no se ha podido analizar. Proba- blemente sea debido al hecho de que los casos se notificaban inmediatamente después de su detección por lo que esta información aún no había sido recogida. Dada la sobrecarga inicial de trabajo en las primeras semanas de la alerta, está información no se pudo actualizar. Al igual que las actuaciones para el manejo de casos y contactos, las recomendaciones e indicaciones de uso de los fármacos antivirales se fueron adaptando durante estos primeros meses basándose en la situación epidemiológica de la infección, el patrón y características de presentación de la enfermedad, la gravedad y letalidad de la misma y las estrategias de vigilancia epidemiológica que se fueron adoptando en todo el Estado. De ahí que se pasara de tratar a todos los casos en investigación y administrar profilaxis a sus contactos al inicio de la alerta, a tratar únicamente a los casos hospitalizados o con riesgo de complicaciones al final del período de estudio.

Durante estos primeros meses tanto la incidencia global de gripe como la mortalidad por todas las causas se situaron por debajo de sus respectivos umbrales basales. En la semana 26 (del 28 de junio al 4 de julio de 2009), la tasa global de incidencia de gripe era aún baja $(11,63$ casos por 100.000 habitantes), con una difusión esporádica de la enfermedad y un nivel bajo de intensidad de la actividad gripal ${ }^{14}$. Sin embargo, la aparición de brotes en colectivos de diferentes características durante el mes de junio de 2009 y el aumento de los casos esporádicos en los que no siempre era posible establecer un vínculo epidemiológico, reflejaba la penetración del virus pandémico (H1N1) 2009 en la comunidad y el inicio de su circulación.

\section{AGRADECIMIENTOS}

La realización de este artículo ha sido posible gracias a los numerosos compañeros de los Servicios de Salud Pública y Laboratorios de las CCAA que han contribuido con 
la vigilancia e investigación de casos de la gripe pandémica (H1N1) 2009. También agradecemos el apoyo de los compañeros del Centro Nacional de Microbiología, Centro Nacional de Epidemiología y Programa de Epidemiología Aplicada de Campo (PE$\mathrm{AC})$. Por último, agradecemos el trabajo y dedicación de los profesionales sanitarios del Sistema Nacional de Salud en toda España.

\section{BIBLIOGRAFÍA}

1. Centers for Disease Control and Prevention (CDC). Swine Influenza A(H1N1) infectionsCalifornia and Texas, April 2009. MMWR Morb Mortal Wkly Rep. 2009; 58:(16):435-7. Disponible en: http://www.cdc.gov/mmwr/preview/mmw $\mathrm{rhtml} / \mathrm{mm} 5816 \mathrm{a} 7 . \mathrm{htm}$.

2. Centers for Disease Control and Prevention (CDC). Outbreak of swine-origin influenza A (H1N1) virus infection-Mexico, March-April 2009. MMWR Morb Mortal Wkly Rep. 2009;58:467-470. Disponible en: www.cdc.gov/ $\mathrm{mmwr} /$ preview/mmwrhtml/mm58d0430a2.htm.

3. World Health Organisation. International health regulations (2005). 2nd ed. 2008. Disponible en: http://www.who.int/ihr/9789241596664/en/index.html (citado el 22 julio 2010).

4. WHO. Statement to the press by WHO DirectorGeneral Dr Margaret Chan, 25 April 2009. Swine influenza. Disponible en: http://www.who.int/mediacentre/news/statements/2009/h1n1_20090425/ en/index.html (citado el 22 julio 2010).

5. WHO. Statement to the press by WHO DirectorGeneral Dr Margaret Chan, 11 June 2009. World now at the start of 2009 influenza pandemic. Disponible en: http://www.who.int/mediacentre/news/ statements/2009/h1n1_pandemic_phase 6 20090611/en/index.html (citado el 22 julio 2010).

6. Ministerio de Sanidad y Consumo. Plan Nacional de Preparación y Respuesta ante una Pandemia de Gripe. Madrid: Ministerio de Sanidad y Consumo; 2005. Disponible en: http://www.msps.es/ciudadanos/enfLesiones/enfTransmisibles/pandemia/ho me.htm (citado el 22 julio 2010).

7. Surveillance Group for New Influenza A(H1N1) Virus Investigation and Control in Spain. New influenza A(H1N1) virus infections in Spain, April-
May 2009. Euro Surveill. 2009;14(19):pii=19209. Disponible en: http://www.eurosurveillance.org/ ViewArticle.aspx?ArticleId=19209.

8. Decisión de la Comisión 2009/363/CE de 30 de abril de 2009 que modifica la Decisión 2002/253/CE por la que se establecen las definiciones de los casos para comunicar las enfermedades transmisibles a la red comunitaria. Disponible en: http://eur-lex.europa.eu/JOHtml.do?uri=OJ:L: 2009:110:SOM:ES:HTML.

9. Health Protection Agency and Health Protection Scotland new influenza $\mathrm{A}(\mathrm{H} 1 \mathrm{~N} 1)$ investigation teams. Epidemiology of new influenza $\mathrm{A}(\mathrm{H} 1 \mathrm{~N} 1)$ in the United Kingdom, April - May 2009. Euro Surveill. 2009;14(19):pii=19213. Disponible en: http://www.eurosurveillance.org/ViewArticle.aspx ?ArticleId=19213.

10. New influenza $A(H 1 N 1)$ investigation teams. New influenza $\mathrm{A}(\mathrm{H} 1 \mathrm{~N} 1)$ virus infections in France, April - May 2009. Euro Surveill. 2009;14(21): pii=19221. Disponible en: http://www.eurosurveillance.org/ViewArticle.aspx?ArticleId=19221.

11. Novel Swine-Origin Influenza A (H1N1) Virus Investigation Team. Emergence of a novel swine-origin influenza A (H1N1) virus in humans. N Engl J Med 2009; 360: 2605-2615. Disponible en: http:// content.nejm.org/cgi/content/full/NEJMoa0903810.

12. Martin J, O'Donnell J, Igoe D, O'Hora A, Thornton L, Murphy N, Cullen G, Fitzgerald M, Cotter $\mathrm{S}$, McKeown P, O'Flanagan D, in conjunction with the National Public Health Outbreak Response Team. Enhanced surveillance of initial cases of pandemic H1N1 2009 influenza in Ireland, April July 2009. Euro Surveill. 2009;14(38):pii=19337. Disponible en: http://www.eurosurveillance.org/ ViewArticle.aspx?ArticleId=19337.

13. Health Protection Agency, Health Protection Scotland, National Public Health Service for Wales, HPA Northern Ireland Swine influenza investigation teams. Epidemiology of new influenza A (H1N1) virus infection, United Kingdom, April-June 2009. Euro Surveill. 2009;14(22):pii= 19232. Disponible en: http://www.eurosurveillance.org/ViewArticle.aspx?ArticleId=19232.

14. Instituto de Salud Carlos III. Boletín semanal del Sistema de Vigilancia de la Gripe en España (SVGE) Semana 26/2009 (del 28 de junio al 4 de julio de 2009). Disponible en: http://www. isciii.es/htdocs/centros/epidemiologia/pdf/grn260 9.pdf (citado el 22 julio 2010). 


\section{Anexo 1}

Ficha para la notificación de casos

FORMULARIO DE NOTIFICACIÓN DE CASO HUMANO DE INFECCIÓN POR NUEVO VIRUS DE LA GRIPE AH1N1

Fecha de Notificación : Comunidad Autónoma: Código ${ }^{1}$

\section{Datos del Notificante}

Médico notificante: Teléfono:

Centro Sanitario:

Dirección (localidad, provincia):

\section{Datos del paciente}

Nombre Paciente: 1er apellido $2^{\circ}$ apellido:

Fecha de nacimiento (dd/mm/aaaa) (edad: Sexo: Hombre $\square \quad$ Mujer $\square$

Domicilio Centro de estudio/trabajo

Municipio y provincia de residencia:

Teléfono:

\section{Admisión hospitalaria}

¿Tenía síntomas cuando ingresó en el hospital? Sí $\square \quad$ No $\square$ Desconocido $\square$

Fecha de ingreso:) (dd/mm/aaaa)

\section{Clínica}

Fecha de Inicio de síntomas:

Fallecido: Sí $\square$ No $\square$ Fecha de defunción: (dd/mm/aaaa)

Fiebre $\left(>38^{\circ} \mathrm{C}\right)$, especificar grados: Sí $\square \quad$ No $\square \quad$ Desconocido $\square$ Tos Sí $\square \quad$ No $\square \quad$ Desconocido $\square$

Cefalea:

Sí $\square \quad$ No $\square \quad$ Desconocido $\square$

Rinorrea:

Sí $\square \quad$ No $\square \quad$ Desconocido $\square$

Dolor de garganta:

Sí $\square \quad$ No $\square \quad$ Desconocido $\square$

Mialgia:

Sí $\square \quad$ No $\square \quad$ Desconocido $\square$

Dificultad respiratoria:

Sí $\square \quad$ No $\square \quad$ Desconocido $\square$

Malestar general:

Si $\square \quad$ No $\square \quad$ Desconocido $\square$

Neumonía

Sí $\square \quad$ No $\square$

Desconocido $\square$

Diarrea

Sí $\square \quad$ No $\square$

Desconocido $\square$

Vómitos:

Sí $\square \quad$ No $\square$

Desconocido $\square$

Otros síntomas:

\section{Antecedentes E pidemiológicos}

A) Estancia o visita a áreas ${ }^{2}$ con casos humanos confirmados de infección por nuevo virus de la gripe AH1N1 durante los 7 días anteriores al inicio de síntomas Sí $\square$ No $\square \quad$ Desconocido $\square$

\footnotetext{
${ }^{1}$ Código: $X X Y Y Y Y\left(X X=\right.$ código CCAA; $Y Y Y Y=n^{\circ}$ de caso, ej: 010001)

${ }^{2}$ Méjico, EE.UU.
}

Rev Esp Salud Pública 2010, Vol. 84, N. ${ }^{\circ} 5$ 
En caso afirmativo, fecha de regres o a España:

(dd/mm/aaaa)

\section{Código ${ }^{3}$}

¿Ha presentado síntomas durante el viaje de regreso? ${ }^{(2)} \quad$ Sí $\square \quad$ No $\square \quad$ Desconocido $\square$

Especificar datos del vuelo (país de origen, número de vuelo, $n^{\circ}$ asiento):

\begin{tabular}{|l|l|l|}
\hline Países/áreas afectadas & Desde (dd/mm/aaaa) & Hasta (dd/mm/aaaa) \\
\hline & & \\
\hline & & \\
\hline & & \\
\hline
\end{tabular}

B) Haber estado en contacto cercano con una persona diagnosticada como caso confirmado o probable de infe cción por nuevo virus de la gripe AH1N1 durante los 7 días anteriores al inicio de síntomas:

Sí $\square \quad$ No $\square \quad$ Desconocido $\square$

\section{¿El contacto ha ocurrido durante su ocupación como trabajador sanitario? $\quad$ Si $\square \quad$ No $\square \quad$ Desconocido $\square$ \\ Especificar:}

\section{¿Se han mantenido las medidas de protección individual recomendadas?} Código del caso primario con el que contactó:

C) Ocupación:

(1) Trabajador sanitario, especificar:

(2) Trabajador de laboratorio/manipulador de muestras

(3) Docente

(4) Trabajadores de residencias de ancianos

(5) Trabajadores de guardería

(6) Otros, especificar:

(9) Desconocido

D) Factores intrínsecos del paciente:

\begin{tabular}{|c|c|c|c|}
\hline Cáncer: & Sí $\square$ & No $\square$ & Desconocido $\square$ \\
\hline Diabetes: & Sí $\square$ & No $\square$ & Desconocido $\square$ \\
\hline VIH / Otra inmunodeficiencia: & Sí $\square$ & No $\square$ & Desconocido $\square$ \\
\hline Cardiopatía: & Si $\square$ & No $\square$ & Desconocido $\square$ \\
\hline Trastornos convulsivos: & Sí $\square$ & No $\square$ & Desconocido $\square$ \\
\hline Enfermedad pulmonar: & Sí $\square$ & No $\square$ & Desconocido $\square$ \\
\hline Embarazo: & meses & No $\square$ & Desconocido $\square$ \\
\hline Malnutrición: & Sí $\square$ & No $\square$ & Desconoc ido \\
\hline
\end{tabular}

Otros:

\section{Diagnóstico de laboratorio}

\begin{tabular}{|l|l|l|l|l|}
\hline \multicolumn{1}{|c|}{ Técnica } & $\begin{array}{c}\text { Laboratorio } \\
\text { donde se ha } \\
\text { realizado }\end{array}$ & Resultado & $\begin{array}{c}\text { Fecha } \\
\text { (dd/mm/aaaa) }\end{array}$ & $\begin{array}{c}\text { Confirmación por } \\
\text { el Centro Nacional } \\
\text { de Microbiología }\end{array}$ \\
\hline RT PCR para virus de la gripe A & & Positivo $\square$ Negativo $\square$ & Sí $\square$ No $\square$ \\
\hline RT PCR para nuevo virus de la gripe AH1N1 & & Positivo $\square$ Negativo $\square$ & & Si $\square$ No $\square$ \\
\hline Cultivo viral de nuevo virus de la gripe AH1N1 & & Positivo $\square$ Negativo $\square$ & & Si $\square$ No $\square$ \\
\hline $\begin{array}{l}\text { Aumento en 4veces en el título de anticuerpos } \\
\text { especificos para nuevo virus de la gripe AH1N1 }\end{array}$ & & Positivo $\square$ Negativo $\square$ & Si $\square$ No $\square$ \\
\hline Test de inmunofluorescencia (IFA) usando & & Positivo $\square$ Negativo $\square$ & & Sí No $\square$ \\
\hline
\end{tabular}

\footnotetext{
${ }^{3}$ Código: $X X Y Y Y Y\left(X X=\right.$ código CCAA; $Y Y Y Y=n^{\circ}$ de caso, ej: 010001) 


\begin{tabular}{|l|l|l|l|}
\hline $\begin{array}{l}\text { anticuerpos monoclonales para nuevo virus de la } \\
\text { gripe AH1N1 }\end{array}$ & & \\
\hline Otros, especificar & & Positivo $\square$ Negativo $\square$ & \\
\hline
\end{tabular}

\section{Código ${ }^{4}$}

\section{Tratamiento}

¿Ha recibido tratamiento (oseltamivir, zanamivir)? Sí $\square$ No $\square$ Desconocido $\square$ En caso afirmativo, nombre del fármaco:

$N^{\circ}$ de días: $(\mathrm{dd} / \mathrm{mm} / \mathrm{aaaa})$

Desde: Hasta

\section{Profilaxis Frente a la Gripe}

$\begin{array}{lll}\text { ¿Se ha vacunado de la gripe en el último año? } & \text { Sí } \square \quad \text { No } \square \quad \text { Desconocido } \square \\ \text { En caso afirmativo, marca comercial: }\end{array}$

Durante los 7 días anteriores al inicio de los síntomas, ¿estuvo tomando algún fármaco antiviral
(oseltamivir, zanamivir, amantadita, rimantadina)?
Sí $\square \quad$ No $\square$
Desconocido $\square$

En caso afirmativo, nombre del fármaco:

Dosis diaria:

$\mathrm{N}^{\circ}$ de días:

Desde:

Hasta

(dd/mm/aaaa)

(dd/mm/aaaa)

Clasificación del caso

CASO EN INVESTIGACIÓN $\square \quad$ CASO PROBABLE $\square \quad$ CASO CONFIRMADO $\square$

CASO DESCARTADO $\square$

${ }^{4}$ Código: $X X Y Y Y Y\left(X X=\right.$ código CCAA; $Y Y Y Y=n^{\circ}$ de caso, ej: 010001)

Rev Esp Salud Pública 2010, Vol. 84, N. ${ }^{\circ} 5$ 
Anexo 2

Ficha notificación de contactos

FORMULARIO DE NOTIFICACIÓN DE CONTACTOS

INFECCIÓN POR NUEVO VIRUS DE LA GRIPE A/H IN1

Fecha de Notificación:

Comunidad Autónoma

\section{Datos del caso (investigación/ probable/ confirmado)}

Código caso ${ }^{5}$

Nombre caso: 1er apellido $2^{\circ}$ apellido:

Fecha de Inicio de síntomas:

\section{Contactos}

¿Cuántos contactos se han identificado para este caso? $\left(n^{\circ}\right)$

\section{Tipo de contactos}

E) Familiares convivientes: $\left(n^{\circ}\right)$

¿Cuantos han recibido profilaxis? $\left(n^{\circ}\right)$

¿Cuántos han desarrollado un cuadro clínico compatible con infección por nuevo virus de la gripe AH1N1? $\left(n^{\circ}\right)$

¿Cuántos han sido confirmados por laboratorio? $(n)$

Por favor, para los contactos que hayan desarrollado sintomas compatibles o hayan sido confirmados, especificar:

\begin{tabular}{|l|l|l|}
\hline Có gc ${ }^{c}$ & Fecha de Inicio de síntomas (dd/mm/aaaa & \multicolumn{2}{|c|}{ ¿Había recibido profilaxis' } \\
\hline- & & Si $\square$ No $\square$ Desconocido $\square$ \\
\hline- & & Si $\square$ No $\square$ Desconocido $\square$ \\
\hline- & Si $\square$ No $\square$ Desconocido $\square$ \\
\hline & & Si $\square$ No $\square$ Desconocido $\square$ \\
\hline
\end{tabular}

F) Amigos: $\left(n^{\circ}\right)$

¿Cuantos han recibido profilaxis? $\left(n^{\circ}\right)$

¿Cuántos han desarrollado un cuadro clínico compatible con infección por nuevo virus de la gripe AH1N1? $\left(n^{\circ}\right)$

¿Cuántos han sido confirmados por laboratorio? $(n)$

Por favor, para los contactos que hayan desarrollado síntomas compatibles o hayan sido confirmados, especificar:

\begin{tabular}{|c|c|c|}
\hline Cór gC' & Fecha de Inicio de síntomas (dd/mm/aaaa & ¿Había recibido profilaxis' \\
\hline[ & & Sí $\square$ No $\square$ Desconocido $\square$ \\
\hline$\longrightarrow$ & & Desconocido $\square$ \\
\hline 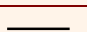 & & Desconocido $\square$ \\
\hline & & Desconocido $\square$ \\
\hline
\end{tabular}

G) Laborales: $\left(n^{\circ}\right) \_$Especificar contactos trabajadores sanitarios

¿Cuantos han recibido prof ilaxis? $\left(n^{\circ}\right)$

¿Cuántos han desarrollado un cuadro clínico compatible con infección por nuevo virus de la gripe AH1N1? $\left(n^{\circ}\right)$

¿Cuántos han sido confirmados por laboratorio? $(n)$

Por favor, para los contactos que hayan desarrollado sintomas compatibles o hayan sido confirmados, especificar:

\footnotetext{
${ }^{5}$ Código: $X X Y Y Y Y\left(X X=\right.$ código $C C A A ; Y Y Y Y=n^{\circ}$ de caso, ej: 010001)

${ }^{6}$ Código: $X X Y Y Y Y\left(X X=\right.$ código $C C A A ; Y Y Y Y=n^{\circ}$ de caso, ej: 010001)

${ }^{7}$ Código: $X X Y Y Y Y\left(X X=\right.$ código CCAA; $Y Y Y Y=n^{\circ}$ de caso, ej: 010001)
} 


\begin{tabular}{|c|c|c|}
\hline Cór gc & Fecha de Inicio de síntomas (dd/mm/aaaa & ¿Hábia recibido profilaxiś \\
\hline$\longrightarrow$ & & Sí $\square$ No $\square$ Desconocido $\square$ \\
\hline & & Desconocido $\square$ \\
\hline 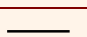 & & Desconocido $\square$ \\
\hline & & Desconocido $\square$ \\
\hline
\end{tabular}

H) Otros: $\left(n^{\circ}\right) \_$(Tipo

¿Cuantos han recibido profilaxis? $\left(n^{\circ}\right)$

¿Cuántos han desarrollado un cuadro clínico compatible con infección por nuevo virus de la gripe AH1N1? $\left(n^{\circ}\right)$

¿Cuántos han sido confirmados por laboratorio? $(n)$

Por favor, para los contactos que hayan desarrollado sintomas compatibles o hayan sido confirmados, especificar:

\begin{tabular}{|c|c|c|}
\hline Cór gC" & Fecha de Inıcıo de sintomas (dd/mm/aaaa) & ¿Habia recibido protilaxıs' \\
\hline- & & Sí $\square$ No $\square$ Desconocido $\square$ \\
\hline 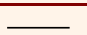 & & Desconocido $\square$ \\
\hline 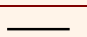 & & Desconocido $\square$ \\
\hline & & Desconocido $\square$ \\
\hline
\end{tabular}

${ }^{8}$ Código: $X X Y Y Y Y\left(X X=\right.$ código $C C A A ; Y Y Y Y=n^{\circ}$ de caso, ej: 010001)

${ }^{9}$ Código: $X X Y Y Y Y\left(X X=\right.$ código $C C A A ; Y Y Y Y=n^{\circ}$ de caso, ej: 010001)

Rev Esp Salud Pública 2010, Vol. 84, N. ${ }^{\circ} 5$ 
Anexo 3

Ficha para notificación de brotes

FORMULARIO DE NOTIFICACIÓN DE BROTES*

INFECCIÓN POR NUEVO VIRUS DE LA GRIPE A (H1N1)

Fecha de la $1^{\text {a }}$ Notificación:

Comunidad Autónoma

Código brote ${ }^{10}$

Datos del brote

Tipo colectivo/institución:

Centro educativo

Sí $\square$

No $\square$

Centro sanitario

Sí $\square$

No $\square$

Residencia de ancianos

Sí $\square$

No $\square$

Guardería

Sí $\square$

No $\square$

Otros

Sí $\square \quad$ Especificar:

\section{Detección:}

Fecha de detección del brote (dd/mm/aaaa):

$N^{\circ}$ de casos a la detección del brote:

Fecha de Inicio de síntomas del primer/os caso/s detectado/s (dd/mm/aaaa):

Total de la población susceptible ${ }^{11}$ (denominador):

\section{Actualización periódica}

Fecha de actualización (dd/mm/aaaa):

$\mathrm{N}^{\circ}$ total de casos confirmados (a fecha de envío):

$N^{\circ}$ total de casos confirmados con complicaciones:

Casos confirmados por vínculo epidemiológico:

Casos confirmados por laboratorio:

Casos con Factores de Riesgo subyacentes:

Casos sin Factores de Riesgo:

Casos se desconoce Factores de Riesgo:

$N^{\circ}$ total de sujetos sospechosos:

Se adjunta envío de curva epidémica:

Sí $\square \quad$ No $\square$

\footnotetext{
${ }^{10}$ Código: $X X-B-Y Y Y Y\left(X X=c o ́ d i g o ~ C C A A ; B=\right.$ constante que identifica el código como de un brote; $Y Y Y Y=n^{\circ}$ de brote, ej: 010001)

${ }^{11}$ Según la definición de territorio epidémico que se haga para el brote (total del aula, colegio...)

* No se consideran las agrupaciones familiares. 